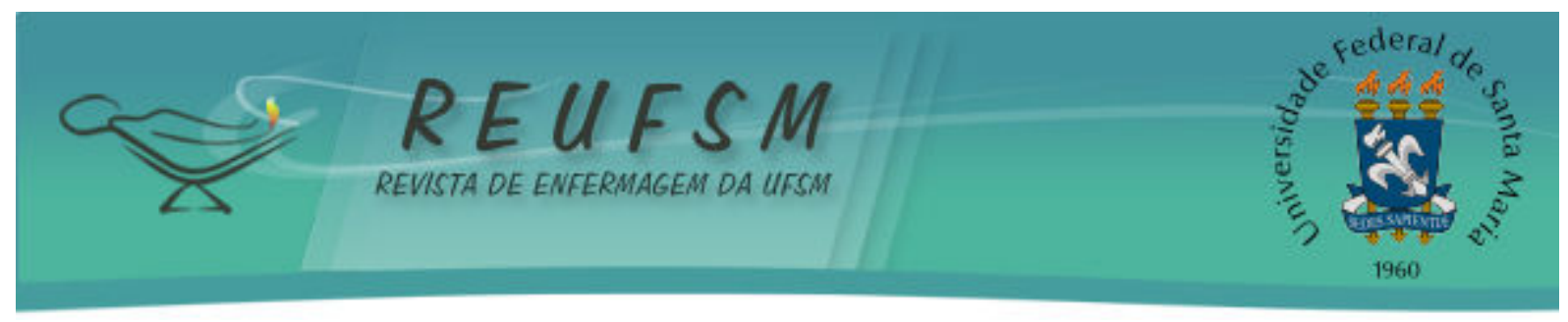

ARTIGO ORIGINAL

\title{
PERCEPÇÃO DOS PACIENTES ACOMETIDOS PELA LEUCEMIA FRENTE À INTERNAÇÃO HOSPITALAR
}

\author{
PERCEPTION OF PATIENTS AFFECTED BY LEUKEMIA ON HOSPITAL ADMISSION \\ PERCEPCIÓN DE LOS PACIENTES AFECTADOS POR LA LEUCEMIA FRENTE A LA \\ HOSPITALIZACIÓN
}

\author{
Daglie Carla Galvan ${ }^{1}$ \\ Graciele Kaufmann ${ }^{2}$ \\ Angela Maria Brustolin ${ }^{3}$ \\ Rosana Amora Ascari ${ }^{4}$
}

Doi: $10.5902 / 2179769211079$

RESUMO: Objetivo: investigar a percepção que o paciente adulto com leucemia atribui sobre o processo de internação hospitalar e enfrentamento da doença. Métodos: trata-se de um estudo exploratório com abordagem qualitativa descritiva, por meio de entrevista semiestruturada desenvolvida de março à abril de 2013 com sete pacientes adultos portadores de leucemia institucionalizados. Os dados foram tratados e analisados pelo método de análise de conteúdo. Resultados: emergiram quatro categorias, sendo elas: Reconhecimento de sinais e sintomas da leucemia; Sentimentos frente à doença; Enfrentamento da doença e do processo de internação; e Mudanças nos hábitos de vida relacionados à internação e o tratamento. Conclusão: o paciente oncológico busca as mais diversas formas de enfrentamento para resistir ao processo da doença e dos abalos físicos e emocionais que a doença traz, bem como, permitem a este paciente repensar sua existência e encontrar formas de resiliência para enfrentar esta condição.

Descritores: Percepção; Leucemia; Enfermagem.

ABSTRACT: Aim: to investigate the perception that the adult patient with leukemia attributes on the process of hospitalization and coping. Methods: this was an exploratory descriptive qualitative approach study, using semi-structured interviews carried out from March to April 2013 with seven adult patients with leukemia institutionalized. Data were processed and analyzed by the method ofcontent analysis. Results: four categories emerged, named: Recognition of signs and symptoms of leukemia; Feelings against disease; Coping with illness and hospitalization process; and Changes in lifestyle-related hospitalization and treatment. Conclusion: cancer patients seek the most diverse forms of coping to resist the disease process and the physical and emotional upheavals that comes with thedisease, as well as, it allows this patient to rethink his life and find resilience paths to face this condition.

Descriptors: Perception; Leukemia; Nursing.

\footnotetext{
${ }^{1}$ Acadêmica de Enfermagem. Universidade do Estado de Santa Catarina - UDESC. Chapecó/SC - Brasil. E-mail: dagui_galvan@hotmail.com

${ }^{2}$ Acadêmica de Enfermagem. Unidade do Estado de Santa Catarina - UDESC. Chapecó/SC - Brasil. E-mail: gracieli.kaufmann@hotmail.com

3 Enfermeira. Especialista em Oncologia. Professora da Universidade do Estado de Santa Catarina - UDESC. Chapecó/SC - Brasil. E-mail: angelabrustolin@yahoo.com.br

${ }^{4}$ Enfermeira. Doutoranda em Enfermagem. Mestre em Saúde Coletiva. Professora Assistente da Universidade do Estado de Santa Catarina - UDESC. Membro do Grupo de Estudos sobre Saúde e Trabalho - Gestra/Udesc. Chapecó/SC - Brasil. E-mail: rosana.ascari@hotmail.com
} 


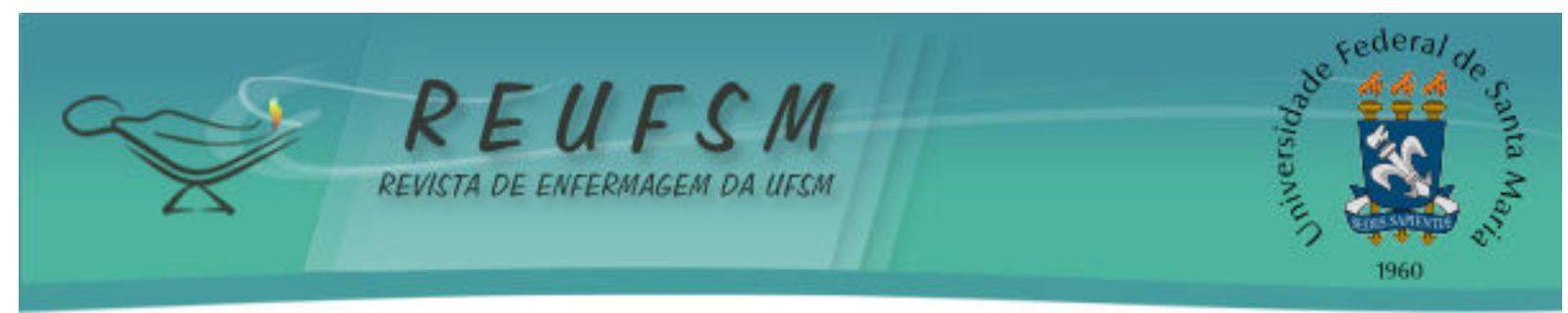

RESUMEN: Objetivo: investigar la percepción que el paciente adulto con leucemia tiene sobre el proceso de hospitalización y de afrontamiento de la enfermedad. Métodos: estudio exploratorio con abordaje cualitativo descriptivo, por medio de entrevista semiestructurada realizadas entre marzo/abril de 2013, con siete pacientes con leucemia institucionalizados. Los datos fueron procesados y analizados por el método de análisis conteúdo. Resultados: emergieron cuatro categorías: reconocimiento de los signos y síntomas de la leucemia, sentimientos delante la enfermedad, Hacer frente a la enfermedad y el proceso de hospitalización; y Los cambios en los hábitos de vida relacionados a la hospitalización y el tratamiento. Conclusión: el paciente busca las más diversas formas de hacer frente para resistir al proceso de la enfermedad y los trastornos físicos y emocionales que la enfermedad trae, así como, permiten a este paciente a replantearse su vida y encontrar formas de resistencia para hacer frente a esta condición. Descriptores: Percepción; Leucemia; Enfermería.

\section{INTRODUÇÃO}

Leucemia é a denominação que se dá para diversos tipos de câncer originados nos tecidos que produzem o sangue, na medula óssea. Essa patologia pode ser aguda ou crônica, dividindo-se ainda entre mielóide (ou mielógena) ou linfóide (ou linfocítica ou linfoblástica). ${ }^{1}$

É uma doença hematológica, que acomete indivíduos de todas as faixas etárias e vem aumentando gradativamente nos últimos anos, devido ao aumento da população idosa, bem como, à maior exposição a fatores de risco cancerígenos e aos atuais padrões de vida adotados em relação ao trabalho, nutrição e consumo em geral. Ao longo do tempo, tem sido considerado, um problema de saúde pública e discutida pelos gestores em saúde, devido a sua complexidade e morbimortalidade.

A leucemia é uma doença maligna dos glóbulos brancos (leucócitos), geralmente, de origem desconhecida. O tratamento bem-sucedido é uma tarefa altamente especializada, pois os pacientes podem ser extremamente suscetíveis a infecções, hemorragias e muitas outras complicações. ${ }^{2}$

O cuidado ao paciente oncológico, com significado atribuído ao câncer, torna-se mais complexo do que outras doenças, pois envolve, além dos aspectos físico-biológicos e socioculturais, os aspectos espirituais das pessoas. Cabe ao enfermeiro, responsável pelo planejamento individualizado da assistência, compreender e valorizar a relação entre a espiritualidade e o enfrentamento ao câncer, na visão do paciente. ${ }^{3}$ Para que este possa passar pelo seu processo de internação de forma mais amena possível e deste modo enfrentar a sua condição de doença.

Diante deste contexto, percebe-se a importância do conhecimento relacionado à leucemia pelos profissionais de enfermagem, para propiciar aos pacientes, conforto e bem estar; visando conhecer as formas de tratamento, acompanhamento psicológico, transplante de medula óssea, qualidade de vida do paciente transplantado, minimizar o sofrimento dos pacientes e familiares, entender os processos de enfrentamento da doença, mais precisamente a leucemia, também esclarecer a população referente ao conceito desta doença, bem como, sinais, sintomas e os órgãos acometidos.

Levando em consideração a essência do cuidado de enfermagem nos serviços de oncologia, emergiu a seguinte questão de pesquisa: Qual a percepção do paciente com leucemia sobre o processo de internação hospitalar e quais as formas utilizadas para o enfrentamento da doença? 0 objetivo deste estudo foi investigar a percepção que 0 paciente adulto com leucemia atribui sobre o processo de internação hospitalar e as formas de enfrentamento da doença. 


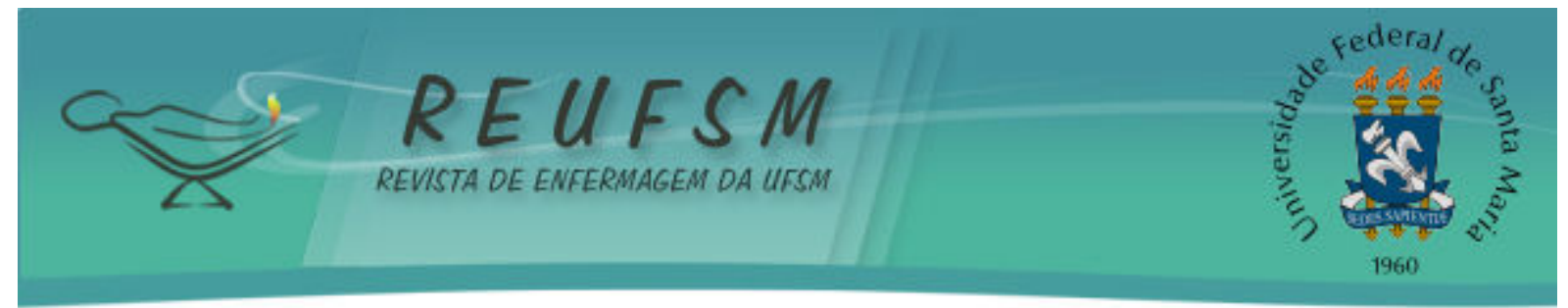

MÉTODO

Estudo exploratório com abordagem qualitativa descritiva, realizado nos meses de março e abril de 2013 em um hospital público de referência no Oeste de Santa Catarina, com pacientes adultos hospitalizados no setor de oncologia. Foram inclusos no estudo pacientes adultos entre 18 e 60 anos, de ambos os sexos, acometidos pela leucemia, internos na clínica oncológica e como exclusão jovens debilitados, com restrições cognitivas, psicológicas ou em fase de nadir período em que o paciente apresenta-se com número de leucócitos mais baixo o que se compreende entre sete a 14 dias pósquimioterapia, estando em isolamento protetor.

A coleta de dados se deu através de entrevista semiestruturada com perguntas abertas acerca da leucemia. Participaram sete indivíduos de ambos os sexos, entre 18 à 44 anos de idade. Todas as entrevistas foram gravadas e posteriormente, transcritas na íntegra e registradas em formulário próprio, individuais por participante. Após foi realizada a análise, interpretação, discussão e categorização dos dados pelo método de análise de conteúdo. ${ }^{4}$ Os participantes tiveram seus direitos preservados e foram informados que sua participação no estudo não oferece riscos de qualquer natureza.

Frente à complexidade do tema e a necessidade de se falar de doença, fato que pode mobilizar sentimentos e recordações negativas, os pesquisadores disponibilizaram ao paciente e família, acompanhamento do serviço de psicologia da própria instituição hospitalar.

Este estudo foi submetido ao Comitê de Ética para Pesquisa em Seres Humanos da Universidade do Estado de Santa Catarina - UDESC, aprovado pelo número do protocolo $\mathrm{n}^{\circ}$ 175.537/2012, em 17 de dezembro de 2012.

O Termo de Consentimento Livre e Esclarecido, conforme determina a Comissão Nacional Éticaem Pesquisa - CONEP, através da Resolução 466/2012 foi assinada por todos os participantes do estudo, sendo que todos passaram por orientações sobre o mesmo. Foram utilizados números arábicos crescentes para a identificação dos participantes, mantendo o anonimato e garantindo o direito a desistir da pesquisa em qualquer tempo, caso assim o desejasse.

\section{RESULTADOS E DISCUSSÃO}

Após as leituras e reflexões do conteúdo produzido por meio das entrevistas com os sete participantes, emergiram quatro categorias, sendo elas: reconhecimento de sinais e sintomas da leucemia, sentimentos frente à doença, enfrentamento da doença e do processo de internação e mudanças nos hábitos de vida relacionados à internação e o tratamento.

\section{Reconhecimento dos sinais e sintomas da leucemia}

Esta categoria apresenta os sinais e sintomas mais comuns da leucemia. Contudo, alguns surgiram antes do diagnóstico da neoplasia, caracterizando o motivo da procura pelo atendimento, e outros foram evidenciados após o início do tratamento.

Acerca da sintomatologia que acometeram os pacientes antes da realização do diagnóstico da leucemia, fazendo com que procurassem atendimento médico por inúmeras complicações, foram queixas de dores musculares e abdominais, edema, fadiga, náusea, inapetência e mal estar geral, conforme as falas a seguir:

Eu estava grávida de cinco meses, daí começou uma dor na barriga, fui na minha cidade, consultei, internei, fizeram os exames, deu tudo alterado. (Paciente 2) 


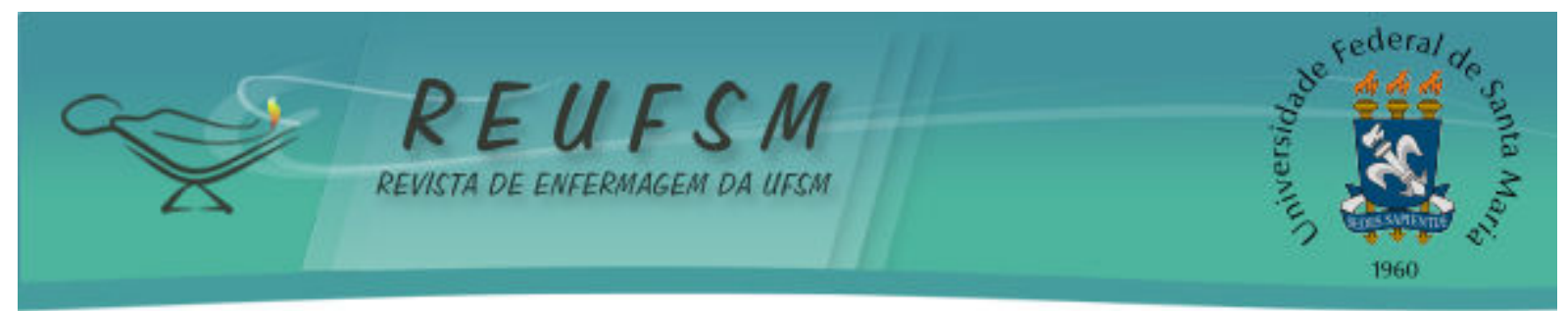

Eu fui fazer um tratamento das amídalas. (Paciente 7)

Frente à suspeita ou presença de alterações hematológicas no sangue, o indivíduo deve procurar um profissional da saúde, que fará um histórico e exame físico completo para identificar algum sintoma ou alteração conforme a suspeita da doença. Será solicitado um hemograma e outros exames. No entanto, apenas uma biópsia da medula óssea é o que confirmará o diagnóstico definitivo. Para alguns casos, poderá ser necessária também uma punção do líquor - líquido presente na medula espinhal. ${ }^{2}$

A grande maioria dos cânceres é descoberta devido aos sintomas que produz ou porque o indivíduo ou o profissional da saúde percebe um caroço ou algo anormal no organismo. ${ }^{2}$ Isso se evidencia com a fala:

Sim, eu vim parar aqui no hospital por causa da trombose. Que me deu na perna, minha perna ficou horrível. Inchada. (Paciente 6)

As doenças neoplásicas podem apresentar diversas alterações musculoesqueléticas e/ou sintomas sistêmicos como febre de origem indeterminada, artrite/artralgia, miosite, vasculite, linfadenopatia e outras alterações tanto no início da doença como durante sua evolução. ${ }^{5}$

0 paciente para enfrentar a hospitalização e todo o ciclo do tratamento, entra em contato com sua própria dor e com a dor de outros pacientes, confronta-se com a impotência, necessidade de apoio, mudanças nos papéis sociais e familiares até então exercidos, alterações na imagem corporal, ansiedade pelo resultado de exames, medo da morte. Este sujeito mergulha nesta nova realidade e precisa encontrar recursos internos próprios para enfrentar a doença, o tratamento e todas as suas repercussões físicas, psicológicas, familiares e sociais. ${ }^{6}$

Os sintomas estão relacionados à piora do estado geral, porque o câncer é uma doença que compromete o corpo inteiro..$^{5-7}$ De acordo com a fala a seguir:

Ah... Eu passava muito mal, tinha muita dor no corpo, ânsia de vômito, vômito também. Tinha força pra nada, só ficava deitado... molenga. Só. (Paciente 3)

Grande parte dos cânceres são descobertos pelos sintomas sistêmicos. ${ }^{2,5}$ Os tratamentos antineoplásicos, ${ }^{7}$ principalmente a radioterapia e a quimioterapia, têm efeitos altamente tóxicos para o paciente, por deixar o organismo debilitado e vulnerável, aumentar o risco para o comprometimento nutricional, sistema imune e prejudicar a resposta terapêutica. Evidenciado nas falas abaixo:

Até que eu estou fazendo as quimioterapias eu me sinto mal [risos], por causa que as reações, elas vem de repente e daí uma hora somem, depois voltam de novo, altera a pressão, dá febre, bastante. (Paciente 1)

Assim, nem comer eu não podia, tinha muitas náuseas. Meu Deus do céu. Só de sentir o cheiro da comida eu já tinha náuseas. (Paciente 6)

As diferentes modalidades de tratamento oncológico ocasionam riscos específicos, podendo definir um padrão de alterações imunológicas para cada estágio e prever o tipo de infecção, e um dos sintomas mais comuns de uma possível infecção é o aparecimento de febre, picos de temperatura elevada. ${ }^{8}$ Destacado nas falas do participante a seguir: 


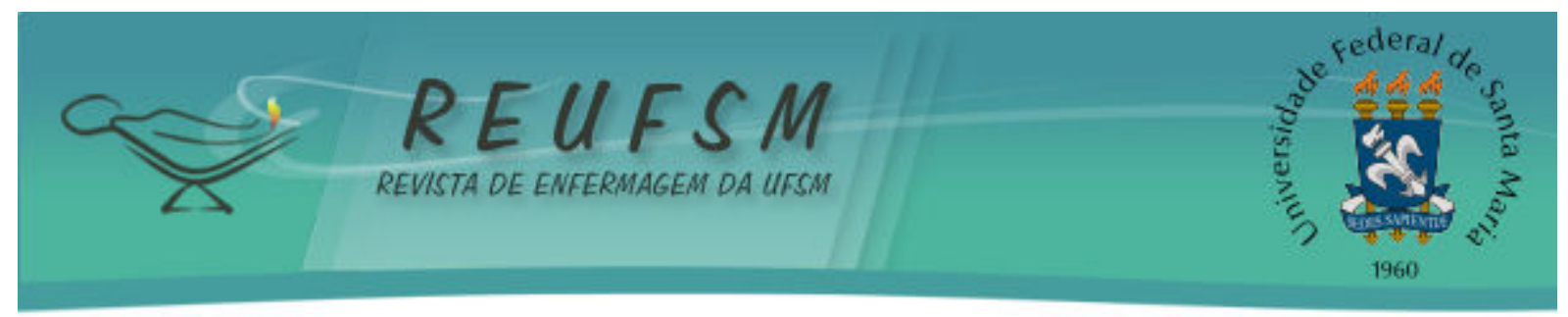

Depois de 60 dias me deu febre alta de novo, manchas nas costas, manchas vermelhas que apareciam e sumiam, altera a pressão. Dá febre, bastante. (Paciente 1)

Odeio febre, [risos] é que daí tem que tirar sangue e que daí dói bem mais tirar sangue com febre do que sem [risos] então é... Acho que a febre é a que mais me incomoda assim né. Eu não gosto de ter febre. (Paciente 1)

É necessário ficar atento para o possível surgimento de infecções dos mais diversos tipos, pois estes pacientes são altamente susceptíveis pela falta ou pouca imunidade, devido à menor contagem hematológica, sinais e sintomas sugestivos de infecção grave (calafrios, hipotensão) devem ser investigados. ${ }^{8}$

\section{Sentimentos frente à doença}

Nesta categoria emerge os principais sentimentos descritos pelos pacientes desde o momento em que recebem o diagnóstico de leucemia, bem como todo o período que compreende todo o processo de tratamento, incluindo os momentos de internação hospitalar. Sendo eles sentimentos positivos e negativos.

Os principais sentimentos negativos mencionados pelos pacientes frente à doença e ao processo de internação foram os sentimentos de tristeza, dor, dor social, medo da morte, medo do desconhecido, insegurança, desespero, negação e fuga.

A leucemia, como toda a patologia oncológica, é uma doença carregada de preconceitos, onde o doente se sente, na maioria das vezes, estranho, afastando-se e enfrentando a solidão. 0 diagnóstico de leucemia está vinculado a muito sofrimento, dor e mutilações físicas e psicológicas. ${ }^{9}$

O câncer ainda é tratado como maldição, sentença de morte, um mau presságio e não simplesmente uma doença. Ainda é vista como uma doença relacionada à dor, morte e sofrimento. ${ }^{10}$ Por isso, em sua maioria, seus portadores se sentem duramente descriminados. 0 estigma que ronda o câncer como sinônimo de deterioração e morte pode dificultar a aceitação da possibilidade do tratamento e da cura, concorrendo para a diminuição da esperança dos pacientes em tratamento, como nas falas dos entrevistados a seguir:

A gente se sente meio incomodada, perder o cabelo né, tem tudo uma, uma coisa que vai junto com a gente né, meu Deus, porque na verdade é o cartão de visita, né.Então sem cabelo tu se olha assim[...]Eu até evito de me olhar. (Paciente 2)

Queria sair correndo, né [risos]. Acostumado fora, nas primeiras semanas eu me senti bastante assim, bem trancado no quarto.(Paciente 1)

Pacientes com doenças crônicas podem passar por cinco fases, sendo elas a negação, raiva, barganha, depressão e a aceitação, estas fases são como mecanismos de defesa para enfrentar o processo desconhecido ou de morrer, em que os conflitos de ordem emocional, material, psicológica, familiar, social, espiritual, entre outros, surgem de forma acentuada, afetando diretamente o relacionamento com a equipe de saúde. ${ }^{11}$

Então tem que deixar as crianças em casa, deixar a casa, meus bichinhos porque eu moro no interior. (Paciente 2 ) 


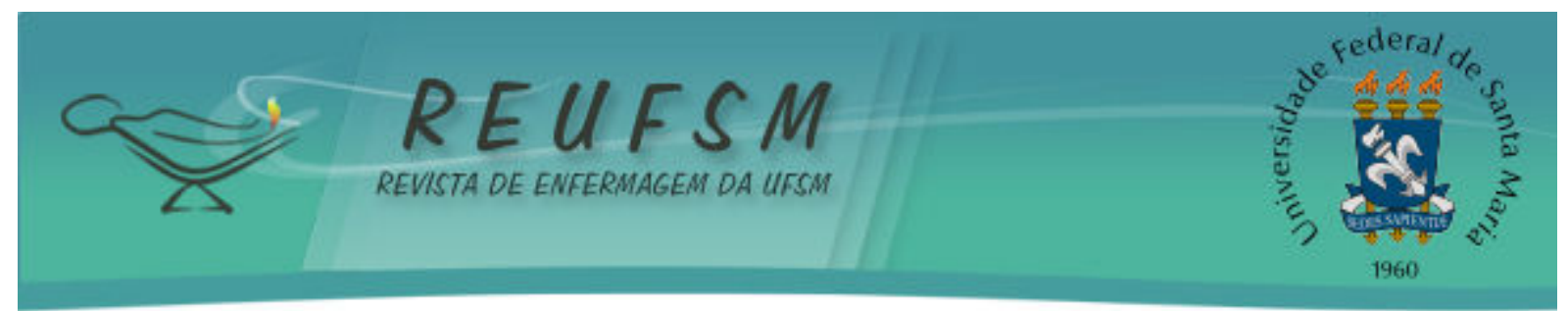

Sim, tive medo de não me curar e de morrer.(Paciente 4)

As pessoas devem compreender a fase da negação, pois, é a reação que mostra a falta de preparação emocional para enfrentar esse momento difícil. ${ }^{12}$ É perceptível nas falas, o desinteresse e a exacerbação do humor, típico da negação frente ao diagnóstico da leucemia.

Para mim tipo, assim. Era diversão, sabe. Eu não estava nem aí, sabe. Porque olha, se tu não sente dor, sabe, se tu tá bem assim, não tem o porque você ficar triste, né. (Paciente 6)

Foi tranquilo ter descoberto, pra mim era uma doença que vem[...] Só é muito cansativo ficar só deitada. De um lado é bom, mas no outro não.Ah, não precisa trabalhar[...]. (Paciente 7)

O período de transição entre a saúde e o adoecimento de câncer afeta a vida dos indivíduos, levando-os a expressarem variados sentimentos e a adotarem comportamentos que os ajudam no enfrentamento do diagnóstico e na adaptação cotidiana ao tratamento requerido pela doença. ${ }^{13}$ Entre os mecanismos usados pelo paciente frente ao diagnóstico de uma doença incurável e terminal, como o câncer, estão os estágios de negação caracterizado pela recusa de acreditar que determinada informação seja verdadeira, gerando isolamento. ${ }^{13}$

O sofrimento da contingência de ter câncer revela-se como um marco divisor produzindo mudanças nas maneiras específicas de viver. ${ }^{13}$

Nas entrevistas, observou-se que os pacientes hospitalizados apresentam sentimentos de esperança relacionados ao tratamento, bem como a chance de cura, otimismo e aceitação.

Esperança é um estado relacionado a uma previsão positiva quanto ao futuro, uma eficaz forma de enfrentamento, expectativa de alcançar um objetivo, algo imprescindível para a vida, a mesma estimula o ser humano a agir, se mover e alcançar. ${ }^{14}$ Foi constatada nas falas a seguir a passagem de fase na psicodinâmica do paciente, da negação para a aceitação.

Tem tratamento, tem cura, então, não é como antigamente que morria as pessoas e não sabia por que. (Paciente 1)

Mas acho que morrer, eu acredito que não, tenho muito ainda pra viver[... ]estou aqui, e vou ainda. Sou teimosa [risos]. (Paciente 6)

No estágio da aceitação não significa que o paciente tome uma atitude cômoda e espere calmamente a morte. Acontece quando o paciente se mostra capaz de entender sua situação atual e as suas consequências. ${ }^{12}$

Agora a gente já sabe mais da doença, já tá mais por dentroné. (Paciente 2)

Todos nós temos uma cruz pra carregar, então é[...] se essa aí é minha, vamos carregar. (Paciente 1)

Agora é aqui que eu vou ter que ficar né. E aceitei de cabeça erguida sabe, enfrentei assim. (Paciente 6) 


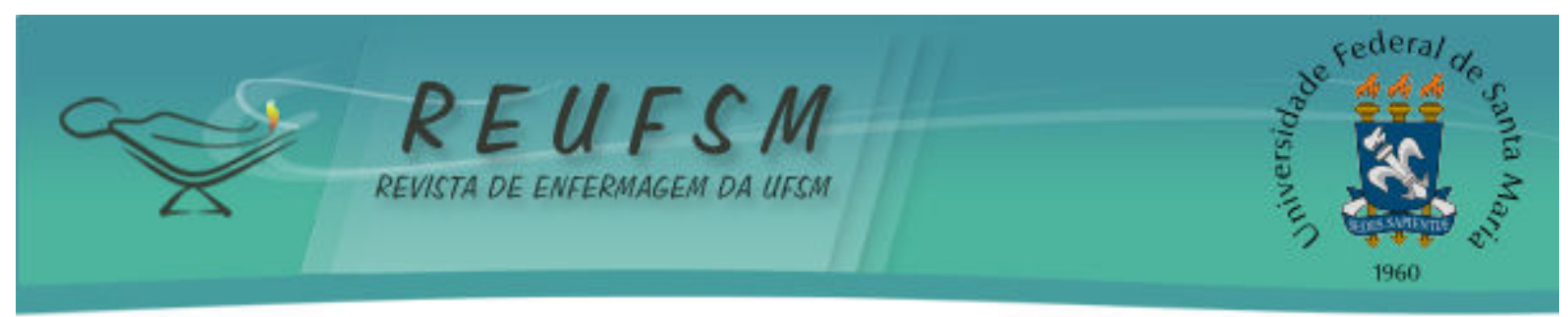

Acontece, agora em um ano vai tem que ser assim, não tem muito querer (Paciente1).

Vai fazer o que né? Se é para o meu próprio bem.(Paciente 3)

Daí depois comecei a aceitar aos poucos. Já que estava aqui tinha que me conformar. (Paciente 4)

Cada ser se percebe conforme a sua leitura de mundo, de acordo com o olhar que tem sobre sua própria doença e forma de vivenciá-la. Dessa forma, independentemente da cultura, cada ser ter uma maneira própria de olhar o mundo ao seu redor, o que se traduz o modo de enfrentamento do cotidiano. ${ }^{15}$ Pesquisa evidenciou no discurso de idosos, sentimento de resignação com o câncer como um desígnio divino que precisa ser aceito, uma missão. ${ }^{15}$

\section{Enfrentamento da doença e do processo de internação}

As formas de enfrentamento mais citadas pelos pacientes foram o apoio familiar, a confiança na equipe multiprofissional, na espiritualidade e fé, também surgiram alguns outros pontos de apoio que puderam ser observados durante a pesquisa. Nas falas a seguir podemos perceber a importância da família:

Mas daí teve bastante apoio, do meu marido que tava presente. (Paciente 2)

Aí eu vi a minha filha sempre aqui comigo, do meu lado né, me dando força. Fora os médicos sabe, as enfermeiras, gente, sabe, foi uma lição muito grande pra mim. (Paciente 6)

A família tem papel relevante junto ao paciente no enfrentamento da doença, incluindo o tratamento e as hospitalizações. ${ }^{16}$ Os familiares irão conviver com o paciente nessa trajetória de descobrimento e terapêutica da neoplasia, sendo um suporte para as perdas e limitações que a doença impõe.

Meus amigos, minha família sou muito apegado. Meus amigos, eles vieram no começo, assim que descobri. Veio um monte de gente assim. (Paciente 3)

A presença dos familiares, dos vizinhos e amigos no hospital possibilita, além de ajuda e distração, também, melhora a manutenção do vínculo da família.

Outra forma de enfrentamento é a espiritualidade, ${ }^{17}$ a prática religiosa é uma estratégia de recuperação das forças perdidas com a doença e durante os tratamentos realizados. A experiência do câncer é um processo que desafia a pessoa e, para tanto, ela busca algo com o qual possa enfrentar esses desafios.

Todos nós temos uma cruz pra carregar, então é[...] se essa aí é minha, vamos carregar. Tem um ditado que [...] um rapaz que carregava uma cruz e 'ah, está muito pesado, vou cortar um pedaço $e$ ia mais um pouco e cortava um pedaço e chegou num barranco $e$ daí tinha os outros deitaram a cruz e passaram, ele não conseguiu porque ele tinha cortado a cruz um pedaço. Então ele teve que 


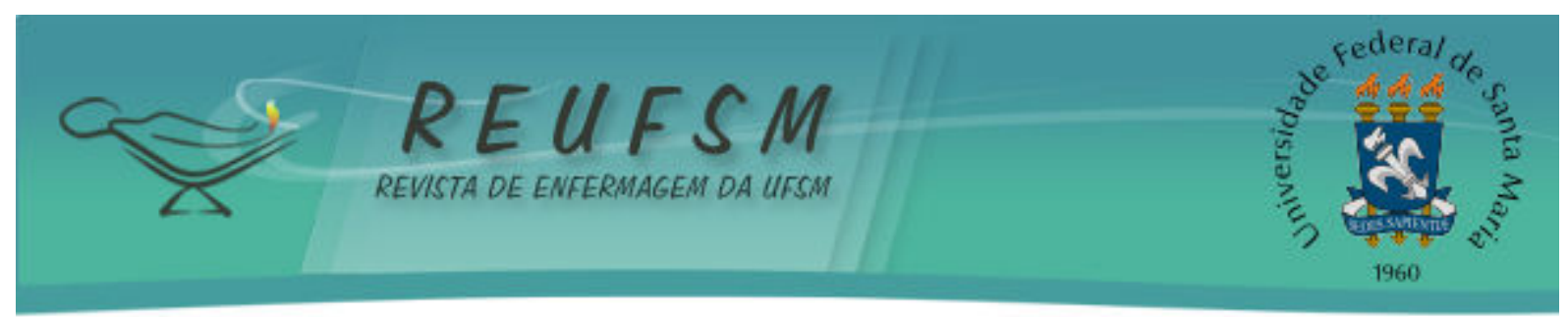

parar por aí'.[...] Então acho que se a gente recebe isso, não deve culpar alguém por ter acontecido isso com a gente, nunca alguém vai querer o mal né. Mas, sempre tentar olhar pelo outro lado. Porque que isso aconteceu? Talvez tenha que acontecer isso pra mim mudar em outra coisa[...] é, é isso [risos]. (Paciente 1)

\section{Mudança de hábitos de vida relacionados à internação e o tratamento}

Essa categoria aponta as principais mudanças nos hábitos de vida desde o momento em que paciente e família receberam a notícia do diagnóstico, durante a internação e todos os ciclos de tratamento da leucemia. Esta categoria expressa o impacto negativo que resultou em alterações na rotina de vida e impactos positivos possibilitando ressignificações de vida e do cotidiano.

As limitações impostas pela doença transformam totalmente a rotina de vida dos pacientes doentes de câncer. Eles se vêem obrigados a submeter-se a um tratamento extremamente agressivo, tendo que adaptarem-se às restrições tanto de atividades quanto de relacionamentos. ${ }^{13,15}$ Pode-se notar na seguinte fala:

Na minha rotina eu saía todos os dias de casa, conversava com pessoas diferentes [...] Então, me sinto angustiado, por não conseguir fazer e os outros fazer e eu não conseguir estar lá, não posso ir no sol, não posso ir na chuva. (Paciente 1)

Então mudou totalmente assim também, para sair de casa fica mais difícil, assim por causa da doença também. (Paciente 2)

Nesses períodos de hospitalização, os pacientes permanecem por um tempo prolongado longe de seu ambiente familiar, de seus objetos pessoais e de seus amigos. Passam a vivenciar situações em que o desconforto e a dor física tornam-se muito intensos, seja pela própria doença ou pelos procedimentos a que são submetidos. ${ }^{13,15}$

Ao experienciar o câncer, o indivíduo é continuamente desafiado a se adaptar e se reestruturar diante as novas situações vivenciadas. Vivenciar o câncer e seu tratamento implica uma experiência marcada por mudanças em todos os aspectos que permeiam sua vida. ${ }^{15}$ repouso:

Nos relatos dos pacientes, pode-se perceber a mudança e o déficit de sono e

Ah, enquanto eu estou fazendo quimioterapia é bastante medicamento, cochila e acorda, cochila e acorda. Se abrir a porta, tu acorda [risos], eu tenho um sono bem leve, mas nos últimos dias que você não tem mais medicamento só recebe plaqueta, sangue de dia, daí é bem tranquilo assim. Durmo sossegado. (Paciente 1)

Os pacientes acometidos pela leucemia correm o risco de apresentar distúrbio no padrão do sono, que é o estado em que o indivíduo apresenta, ou corre o risco de apresentar, uma mudança na quantidade e na qualidade do seu repouso, causando desconforto ou interferindo no estilo de vida desejado. ${ }^{18}$

A capacidade de superação de situações adversas e de dar um novo sentido à vida originou o termo resiliência. As crenças do paciente e aquelas compartilhadas com a família contribuem para a resiliência, pois influenciam no modo como agirão diante de dificuldades. ${ }^{19}$ 


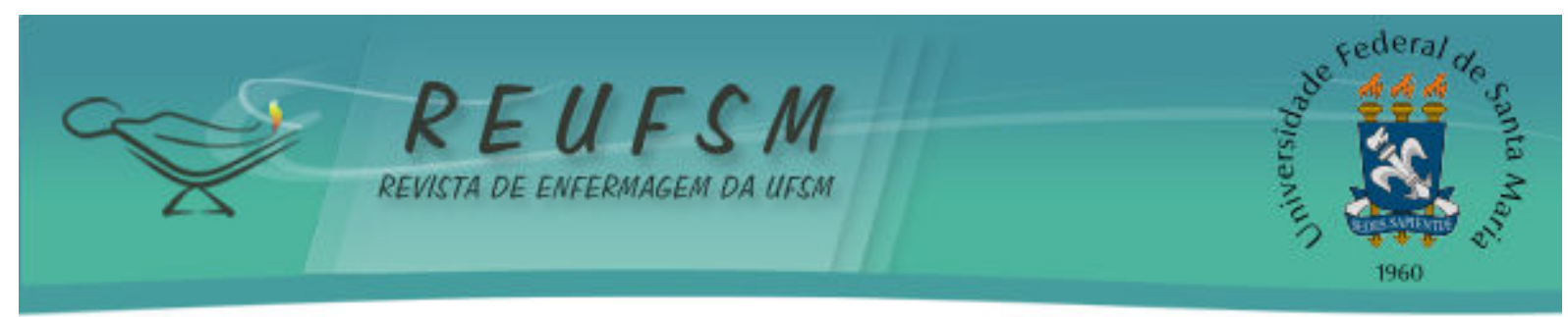

Por que a gente não dá atenção pra saúde sabe, não dá mais tempo, você não procura fazer uma coisa assim mais[...] Mais funda né. E daí eu com essa agora, sabe. Eu prefiro me cuidar agora sabe.(Paciente 6)

O paciente para enfrentar a hospitalização e todo o ciclo do tratamento, entra em contato com sua própria dor, confronta-se com a impotência, com a necessidade de apoio, com as mudanças nos papéis sociais, com as alterações na imagem corporal, com a ansiedade pelo resultado de exames, com o medo da morte. Este sujeito mergulha nesta nova realidade e precisa encontrar recursos internos próprios para enfrentar a doença, o tratamento e todas as suas repercussões físicas, psicológicas, familiares e sociais. ${ }^{6}$

\section{CONCLUSÃO}

O paciente oncológico é um ser especial, que, juntamente, com sua família busca as mais diversas formas de enfrentamento para resistir ao processo total da doença e de todos os abalos físicos e emocionais que a doença traz.

O cenário oncológico possibilita tomar consciência dos processos de finitude que permitem a este paciente repensar sua existência e encontrar formas de resiliência para enfrentar toda esta condição.

Diante das vivências apresentadas, foi possível à compreensão dos sentimentos e percepções do paciente adulto com leucemia acerca do processo de internação e dos mecanismos de enfrentamento utilizados para adaptar-se ou ainda resignificar sua cotidianidade.

Embora já se tenha grandes avanços tecnológicos no tratamento e cura da leucemia, esta ainda é um tipo de câncer que se encontra vinculado à ideia de sofrimento e terminalidade gerando sentimentos de medo, angústia, tristeza e impotência diante da doença. Porém, da experiência do processo de adoecimento emergem sentimentos de positividade, onde 0 ser humano busca mecanismos de enfrentamento como a espiritualidade e o apoio emocional da equipe e da família para vivenciar esta condição.

0 estudo permitiu a compreensão de como o paciente com leucemia vivencia a hospitalização e de seus mecanismos de enfrentamento diante de sentimentos paradoxais. Bem como, acena para a compreensão de que o câncer é capaz de desencadear modificações que transcendem o físico, causando alterações emocionais, espirituais e sociais para o paciente/família.

A hospitalização e o tratamento alteram o cotidiano e modificam os sentimentos do paciente oncológico. Portanto, compreender a complexidade desta condição na ótica do ser cuidado é ponto de partida para o cuidado de enfermagem integral e planejado em todas as fases do tratamento da leucemia.

Neste contexto o estudo vislumbra novas formas de cuidar do paciente com leucemia na medida em que esclarece seus sentimentos e aponta as redes de apoio multiprofissionais como forma de enfrentamento. Apontado para a necessidade de planejamento individualizado de assistência, com vistas a transcender a impessoalidade do cuidado, oportunizando a humanização da assistência de enfermagem ao paciente oncológico.

As limitações do estudo estão relacionadas principalmente a dois fatores, um pelo baixo número de pacientes adulto/jovens em tratamento de leucemia hospitalizados no período da pesquisa, e outro, pela oposição médica que um de seus pacientes participasse da entrevista devido ao estado psicológico de sofrimento e dor causada pela recidiva da doença. Por fim, encontramos poucas bibliografias referentes ao acometimento do público 


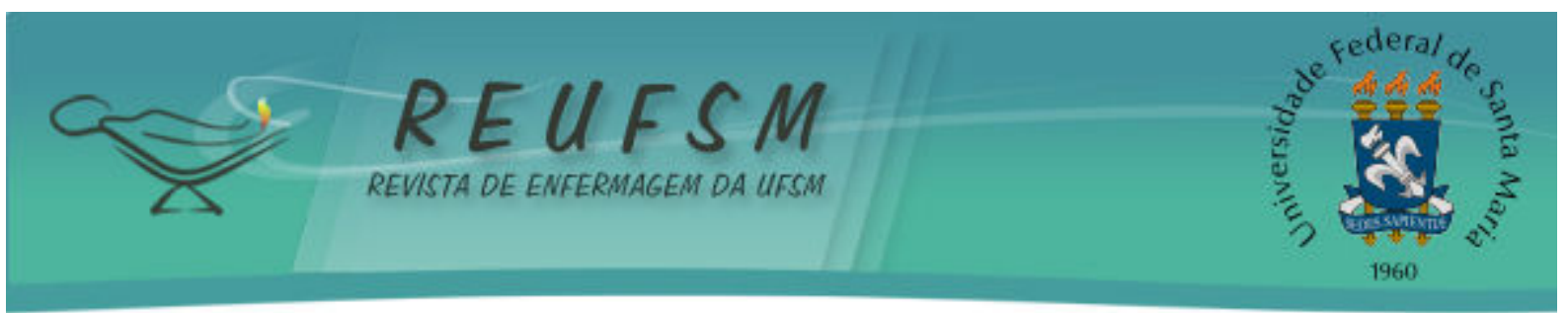

adulto/jovem pela leucemia, a grande maioria dos estudos publicados aborda o tema quanto ao acometimento e tratamento de leucemia em crianças.

\section{REFERÊNCIAS}

1. Zelmanowics $A M$. Leucemia. $A B C$ da Saúde: informações médicas [Internet]. 2010. [acesso em 2012 nov 22]. Disponível em: http://www.abcdasaude.com.br/artigo.php?680.

2. Instituto Nacional do Câncer (INCA). Leucemia [Internet]. [acesso em 2013 jun 22]. Disponível

em:

http://www2.inca.gov.br/wps/wcm/connect/tiposdecancer/site/home/leucemia/definicao.

3. Guerrero GP, Zago MMF, Sawada NO, Pinto MH. Relação entre espiritualidade e câncer: perspectiva do paciente. Rev Bras Enferm. 2011 [acesso em 2012 jun 4];64(1):53-9.

4. Minayo MCS. O desafio do conhecimento: pesquisa qualitativa em saúde. 12a ed. São Paulo: Hucitec; 2010.

5. Campos LMA, Goldstein S, Santiago RA, Jesus AA, Cristofani LM, Odone Filho V, et al. Comprometimento musculoesquelético como primeira manifestação de neoplasias. Rev Assoc Med Brás [Internet]. 2008 [acesso em 2013 out 4];54(2):132-8. Disponível em: http://www.scielo.br/pdf/ramb/v54n2/a15v54n2.pdf.

6. Vasconcellos EA. Imagens simbólicas no adoecer: estudo descritivo sobre o processo arteterapêutica de pacientes oncológicos [Internet]. Campinas (SP); 2004 [acesso em 2013 maio 4]. Disponível

em: http://www.bibliotecadigital.unicamp.br/document/?code=vtls000341734.

7. Elman I, Pinto e Silva MEM. Crianças portadoras de leucemia linfóide aguda: análise dos limiares de detecção dos gostos básicos. Rev Bras Cancerol. 2007 [acesso em 2013 mar 5];53(3):297-303. Disponível em: http://www.inca.gov.br/rbc/n_53/v03/pdf/artigo3.pdf

8. Garnica M, Nucci M. Epidemiologia, tratamento e profilaxia das infecções na leucemia linfóide crônica. Rev Bras Hematol Hemoter [Internet]. 2005 [acesso 2013 out 2];27(4):290300. Disponível em: http://www.scielo.br/pdf/rbhh/v27n4/v27n4a16.pdf.

9. Lameiro D. O acompanhamento psicológico da criança com leucemia [Internet]. 2009 set [acesso em 2013 mar 5]. Disponível em: http://dentalria.com/manage/Leucemia.pdf.

10. Salimera AMO, Teixeira SR, Amorim TV, Paiva ACPC, Melo MCSC. Estratégias de enfrentamento usadas por enfermeiros ao cuidar de pacientes oncológicos. Rev Enferm UFSM [Internet]. 2013 [acesso em 2013 jul 28];3(1):8-16. Disponível em: http://cascavel.ufsm.br/revistas/ojs-2.2.2/index.php/reufsm/article/view/6638.

11. Susaki TT, Silva MJP, Possari JF. Identificação das fases do processo de morrer pelos profissionais de enfermagem. Acta Paul Enferm [Internet]. 2006 [acesso em 2013 jun 22];19(2):144-9. Disponível em: http://www.scielo.br/pdf/ape/v19n2/a04v19n2.pdf.

12. Borges ADVS, Silva EF, Toniollo PB, Mazer SM, Martins do Vale ER, Santos MA. Percepção da morte pelo paciente oncológico ao longo do desenvolvimento. Psicol Estud [Internet]. 2006 [acesso em 2013 jun 28];11(2):361-9. Disponível em: http://www.scielo.br/pdf/pe/v11n2/v11n2a14.pdf.

13. Xavier ATF, Ataide MBC, Pereira FGF, Nascimento VD. Análise de gênero para o adoecer de câncer. Rev Bras Enferm [Internet]. 2010 [acesso em 2013 out 6];63(6):921-6. Disponível em: http://www.scielo.br/pdf/reben/v63n6/08.pdf. 


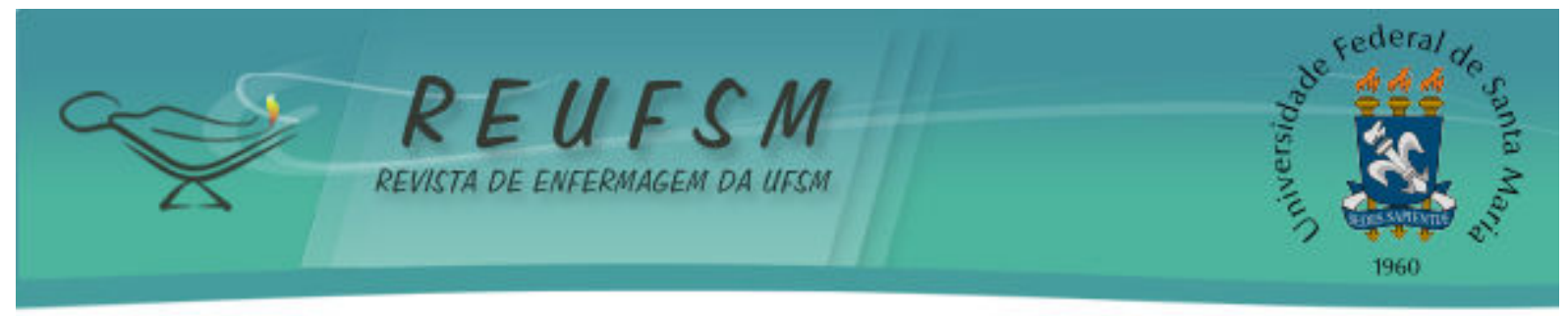

14. Sartori AC, Grossi SAA. Escala de Esperança de Herth - Instrumento adaptado e validado para a língua portuguesa. Rev Esc Enferm USP [Internet]. 2008 [acesso em 2013 mar 5 ];42(2):227-32. Disponível em: http://www.scielo.br/pdf/reeusp/v42n2/a02.pdf.

15. Soares LC, Santana MG, Muniz RM. O fenômeno do câncer na vida de idosos. Ciênc Cuid Saúde [Internet]. 2010 [acesso em 2013 out 6];9(4):660-7. Disponível em: http: / / periodicos.uem.br/ojs/index.php/CiencCuidSaude/article/download/7785/7182.

16. Visoná $F$, Prevedello $M$, Souza EN. Câncer na família: percepções de familiares. Rev Enferm UFSM [Internet]. 2012 [acesso em 2013 mar 5];2(1):145-55. Disponível em: http://cascavel.ufsm.br/revistas/ojs-2.2.2/index.php/reufsm/article/view/3943.

17. Aquino VV, Zago MMF. O significado das crenças religiosas para um grupo de pacientes oncológicos em reabilitação. Rev Latinoam Enferm [Internet]. 2007 [acesso em 2013 mar 5];15(1):42-7. Disponível em: http://www.scielo.br/pdf/rlae/v15n1/pt_v15n1a07.pdf.

18. Souza BF, Pires FH, Dewulf NLS, Inocenti A, Silva AEBC, Miasso Al. Patients on chemotherapy: depression and adherence to treatment. Rev Esc Enferm USP [Internet]. 2013 [acesso em 2013 out 2];47(1):61-8. Disponível em: http://www.scielo.br/pdf/reeusp/v47n1/en_a08v47n1.pdf.

19. Naressi DA, Girardon-Perlini NMO, Sand ICPVD, Beuter M, Rosas BVC. Beliefs and resilience in patients who are survivors of leukemia. J Nurs UFPE on line [Internet]. 2013 [acesso em 2013 jun 4];7(1):67-75. Disponível em: http: //www.revista.ufpe.br/revistaenfermagem/index.php/revista/article/view/3253/pdf -1812.

Data de recebimento: $22 / 10 / 2013$

Data de aceite: 15/01/2014

Contato com autor responsável: Rosana Amora Ascari

Endereço postal: Rua 14 de Agosto, 807 E, Apartamento 301, Bairro: Presidente Médice, CEP: 89.801-251, Chapecó/SC, Brasil.

E-mail: rosana.ascari@hotmail.com ou rosana.ascari@udesc.br 